\title{
O educador social: uma função socioeducativa ou de segurança?
}

\author{
The social educator: a social function or security?
}

\author{
Wilian Leandro dos Santos* \\ Marcio Antunes da Silva ${ }^{* *}$
}

\begin{abstract}
Resumo:
O presente estudo pretende verificar se existem variações entre a função descrita para o cargo de Educador Social no Quadro Próprio do Poder Executivo do Estado do Paraná - QPPE/PR e sua prática, buscando trazer elementos e indicativos para uma avaliação que proporcione o aprimoramento da prática dentro dessa profissão, considerando suas complexidades. Ao final, concluímos que as atividades ligadas à segurança frequentemente são priorizadas em detrimento às de socioeducação.
\end{abstract}

Palavras-chave: Socioeducação. Adolescência. Educador social.

\begin{abstract}
:
This study aimed to assess whether there are variations between the function described for the post of Social Educator in Table Own the Executive Branch of the State of Parana - QPPE/PR and their practice, looking for bringing elements and indicative for an assessment that provides the improvement of practice within this profession, considering theirs complexities. At the end we concluded that the safety-related activities are often given priority over those of socioeducation.
\end{abstract}

Keywords: Social education. Teenager. Social educator.

\section{Introdução}

O presente estudo aborda as questões relacionadas à função do Educador Social, especificamente daqueles que atuam no Centro de Socioeducação - CENSE Londrina II. Para tanto, apresentamos aos Educadores Sociais a descrição básica do cargo, em que constam as atribuições específicas, procurando analisar se, no momento da intervenção junto aos adolescentes, ocorre o que está previsto legalmente ou se há distorções na execução da função.

\footnotetext{
* Professor de Educação Física pela UEL, Educador Social da Secretaria de Estado da Família e Desenvolvimento Social do Paraná, Especialista em Gestão de Centros de Socioeducação pela UEL. wilianenessa@hotmail.com

** Assistente Social, Mestre em Serviço Social e Políticas Sociais pela UEL, Docente Colaborador do Departamento de Serviço Social da UEL marcio.antunes@gmail.com
} 
Inicialmente, tratamos do adolescente e suas particularidades, a fim de entender a complexidade que compreende a adolescência, logo, entendendo também o universo de atuação do Educador Social, pois este é o seu público alvo.

Em seguida, como não poderíamos deixar de fazer, discutimos a questão do adolescente e o ato infracional, para que além das características do adolescente, pudéssemos nos aprofundar especificamente no assunto, o que muda não só a abordagem, mas a própria percepção do adolescente, pois estes estão sob a custódia do Estado por um período.

Por fim, foi feito um levantamento do desenvolvimento histórico da socioeducação em Londrina para que pudéssemos ter a visão do contexto de acontecimentos ocorridos nesta área no município, e como chegamos ao modelo de hoje. Além disso, discutimos como se deu a construção do CENSE Londrina II, o que certamente trás reflexos para a realidade de trabalho desenvolvido e suas condições na atualidade.

O objetivo do presente estudo foi o de comparar e analisar as questões ligadas à prática profissional do Educador Social em relação à descrição do cargo. Ainda buscamos investigar se existe uma preocupação de fato desses profissionais para que o sujeito, Educador Social, seja parte do processo de reinserção social do adolescente que cumpre medida socioeducativa de internação, para que haja um desenvolvimento integral desse indivíduo, sendo um sujeito autônomo, solidário e competente, transcendendo os limites do CENSE Londrina II para que possa desenvolver aptidões pessoais, sociais, produtivas e cognitivas, juntamente com as competências do aprender a ser, aprender a conviver, aprender a fazer e aprender a aprender. Para tanto, verificamos se existem condições para que tal trabalho possa ser desenvolvido de forma plena pelos Educadores Sociais.

\section{Os adolescentes e suas particularidades}

A adolescência é uma fase da vida onde as dúvidas e incertezas são características marcantes de um período de grandes transformações. Por conta desse período de mudanças e crescimento desordenados, temos também um período de grande vulnerabilidade em que a busca por uma aceitação ou mesmo identidade pode provocar uma série de atitudes de rebeldia na busca de autoafirmação. Segundo os Cadernos do IASP (OMS apud INSTITUTO DE AÇÃO SOCIAL DO PARANÁ, 2006, p. 15) “[...] a 
adolescência compreende a faixa etária entre 10 e 20 anos, enquanto o Estatuto da Criança e do Adolescente - ECA (Lei Federal 8.069/90) restringe essa faixa etária entre 12 e 18 anos". Essa é uma demonstração de que a adolescência é uma fase de tamanha complexidade, que gera interpretações subjetivas nas mais conceituadas entidades, sobre - adolescente propriamente dito. Os já mencionados Cadernos do IASP definem adolescência como uma etapa de evolução da vida do homem, caracterizada pela transição da fase da infância para a fase adultícia. Uma consideração importante é sem duvida quando se afirma que:

Embora as etapas estejam definidas em faixas etárias, na realidade, são determinadas, também, mais pela experiência do que pela idade, mais pelo comportamento do que pela aparência e mais pelo significado interior do que pela aparência exterior (INSTITUTO DE AÇÃO SOCIAL DO PARANÁ, 2006, p. 15).

Portanto, a partir dessas definições percebemos o quão complexa é a estrutura do adolescente, podendo nos apresentar algo que vai além do que vemos com olhos ao senso comum, vindo a nos surpreender com condutas que necessitam de uma avaliação mais crítica e menos empírica, um olhar busca qualificar nossa investigação da realidade, conforme nos afirma Freire (2002, p. 31), "É pensando criticamente a prática de hoje ou de ontem que se pode melhorar a próxima prática. O seu distanciamento epistemológico da prática enquanto objeto de sua análise, deve dela aproximá-lo ao máximo".

A prática educativa apresenta-se de forma única, diferente da metodologia usada com as crianças e da metodologia utilizada com os adultos, pois a adolescência é um momento de transição entre as duas fases. Segundo Costa (2000, p. 22):

[...] as crianças são heterônomas (dirigidas a partir de fora), já os adultos são ou deveriam ser autônomos (dirigidos a partir de dentro, de si mesmos) e os adolescentes não se enquadram como heterônomos como as crianças e nem como autônomos como os adultos. Eles são detentores na verdade de uma autonomia relativa. A vida do adolescente é marcada por uma sucessão de circunstancias e situações em que a autonomia e a heterônomia se alternam e às vezes até se superpõem. Estes fatos geram situações confusas tanto para os adolescentes como para seus pais e educadores.

Certamente, essas questões apresentadas contribuem para que o trabalho na socioeducação seja extremamente complexo e cheio de particularidades, que quando 
compreendidas podem sem dúvida contribuir para encaminhamentos com mais qualidade.

\section{$O$ adolescente, a lei e $o$ ato infracional}

Atualmente no contexto brasileiro, ainda existe uma grande desigualdade social que contribui para que o problema do adolescente envolvido em ato infracional tenha uma significância muito grande a exemplo do quadro nacional, fato este que podemos mensurar a partir de dados do documento do Sistema Nacional de Atendimento Socioeducativo - SINASE, que afirma que:

\footnotetext{
O Brasil possui 25 milhões de adolescentes na faixa etária entre 12 e 18 anos, o que representa $15 \%$ da população. É um país repleto de contradições e marcado por uma imensa desigualdade social reflexo da concentração de renda, tendo em vista que $01 \%$ da população rica detém $13,5 \%$ da renda nacional, contra $50 \%$ mais pobres que detém $14,4 \%$ desta. Esta desigualdade social constatada nos indicadores sociais, trás consequências diretas nas condições de vida da população infanto juvenil (IBGE, 2004 apud BRASIL, 2006).
}

A exemplo do que é constatado em nível nacional, Londrina e o estado do Paraná não fogem desse quadro de desigualdade social e, principalmente, das consequências na vida da população infantojuvenil. Sendo a adolescência uma fase de tamanhas transições e mudanças, tais desigualdades têm consequências ainda piores, como, por exemplo, quando os adolescentes se envolvem com atividades criminosas. Diante deste quadro, e munido de uma autonomia relativa, o adolescente que comete ato infracional poderá receber uma medida socioeducativa aplicada pelo Poder Judiciário, conforme previsto no ECA artigo 112, como segue: Advertência; Obrigação de Reparar o Dano; Prestação de Serviço à Comunidade; Liberdade Assistida; Inserção em Regime de Semiliberdade, Internação em Estabelecimento Educacional (BRASIL, 1990).

A medida socioeducativa de internação é aquela que se dá por determinação judicial, na qual o adolescente é obrigado a cumpri-la, ficando no mínimo seis meses, no máximo três anos. Nela, o adolescente fica privado de liberdade, ou seja, o único direito que dele está suspenso é o de liberdade. Isso significa que se deve garantir todos os demais direitos previstos pela ECA. 
Uma vez inserido em cumprimento de medida socioeducativa de internação em unidade de socioeducação, na qual os Educadores Sociais sujeitos da presente pesquisa atuam, o adolescente é amparado por uma série de garantias previstas no ECA, as quais devem ser atendidas com a consciência de que não cabe ao Educador imputar a medida socioeducativa, mas garantir que esta seja executada em sua plenitude. Podemos observar conforme consta nos Cadernos do IASP que "o papel do educador é de criar espaços, organizar meios e produzir acontecimentos que façam a educação acontecer" (COSTA, 2001 apud INSTITUTO DE AÇÃO SOCIAL DO PARANÁ, 2006, p. 46).

Quando começamos a nos aprofundar no estudo do ECA, observamos que existe uma falsa percepção de haver um excesso no que se refere à garantia de diretos para a criança e o adolescente. Tal situação, para muitos soa como banal ou até mesmo desnecessária, por se tratar de assuntos considerados básicos, porém, para compreender tantos detalhes é preciso um olhar histórico e social que trás consigo uma trajetória de violência, omissão e abandono.

Segundo Coelho (2006), no período do Brasil Império, as crianças não desejadas eram encaminhadas para as então chamadas "Roda dos Expostos" ou "Roda dos Excluídos", nas quais eram deixadas por serem pessoas com problemas físicos, mentais, assim como aquelas provenientes de relacionamentos extraconjugais, e ali permanecendo sem qualquer tipo de assistência até a chegada de sua morte precoce.

Ainda para a autora citada, uma das primeiras intervenções no atendimento à criança e ao adolescente se deu em 1924 com a nomeação do 1o Juiz de Menores do Brasil, José Cândido de Albuquerque Mello Mattos, o que coincidiu com relatos de um Jornal Higienista da época, que começou a divulgar a forma diferenciada com que os pobres eram tratados nos Estados Unidos da América. Para os norte-americanos, essa população era uma fonte de riquezas ao invés de um problema como se pensava aqui. Alguns anos mais tarde, foi decretada a primeira lei que tratava sobre questões relacionadas a crianças e adolescentes no país: o decreto $17.943-A$ de 12 de outubro de 1927, certamente um marco na história da atenção à infância em nosso país. Essa primeira lei foi chamada de Código de Mello Mattos.

O Código de Mello Mattos teve vigência até 1979, quando então é substituído pelo Código de Menores, o qual se propunha a cuidar de forma diferenciada do adolescente 
que se encontrasse em situação irregular. No entanto, as diferenças são mínimas entre as duas Leis, sendo que de qualquer situação, seja ela de abandono ou um ato infracional, era tratada de maneira similar, como situação irregular.

Passados 11 anos, em 13 de julho de 1990, é promulgada a Lei Federal 8069, instituindo o Estatuto da Criança e do Adolescente, lei esta que chega com a incumbência de garantir, de forma integral, os diretos da criança e do adolescente, seja ele autor de ato infracional ou não, garantindo ao segmento proteção integral. É importante ressaltar que houve ampla participação dos movimentos sociais, profissionais e militantes na defesa dos direitos humanos, da sociedade civil em geral, na Assembleia Constituinte para a elaboração da presente lei, que vigora até os dias atuais.

\title{
A socioeducação em Londrina
}

O trabalho no âmbito da socioeducação em Londrina tem uma história muito recente. Uma das primeiras iniciativas do poder público estadual foi a criação do CEMIC Centro do Estudo do Menor e Integração à Comunidade. Lolis (apud COELHO, 2006, p. 43) aponta que:

\begin{abstract}
O CEMIC da Vila Fraternidade, local da primeira favela surgida em Londrina, foi criado em 1982 em função do alto numero de crianças e adolescente que passavam pela delegacia, provenientes daquele bairro. 0 próprio juizado de menores (hoje da Infância e da Juventude) solicitou a Prefeitura o atendimento da faixa etária entre 07 á 14 anos [...] Esta entendia meninos e meninas de rua, encampando um trabalho que vinha sendo desenvolvido nas ruas por educadores voluntários, integrantes do Movimento Nacional de Meninos e Meninas de Rua de Londrina [...] O número de crianças e adolescentes de rua era crescente, criando-se também um albergue infantil para o atendimento a essa população.
\end{abstract}

Nessa época, a sigla CEMIC trazia consigo o peso da palavra "MENOR" que remetia a uma associação direta com um rótulo não condizente com o que se esperava de uma convivência saudável em sociedade, como percebemos na fala a seguir:

A doutrina do direito utilizava o termo "MENOR" para estabelecer uma distinção entre "infância normal" (infância família, infância escola, infância protegida e fruindo os bens materiais e culturais e socialmente produzidos) e a "infância desviante" (o contrario da infância normal) [...] cujo conceito estava 
embutido a idéia de carência/delinqüência (MACHADO apud COELHO, 2006, p. 22).

Em 17 de novembro de 1992, foi criado o Serviço Auxiliar da Criança e Juventude (SAI) pela portaria 12/92 subordinado à Secretaria de Justiça com objetivo de executar medidas socioeducativas de Liberdade Assistida. $\mathrm{O}$ atendimento inicial aos adolescentes que cometiam delitos era feito pelo Centro de Estudos Diagnósticos e Iniciação de Tratamento (CEDIT). O Serviço de Triagem e Encaminhamento de Menores (SETREM) veio substituir o (CEDIT), funcionando em uma ala anexada ao 2 ㅇ Distrito Policial sem qualquer infraestrutura. Segundo Coelho (2006, p. 50):

O objetivo do SETREM era zelar pela integridade física, mental, emocional e social dos adolescentes, cabendo-Ihe adotar os procedimentos adequados de contenção e segurança. Os adolescentes que recebiam medida de internação eram encaminhados ao Educandário São Francisco na região Metropolitana de Curitiba.

Em outubro de 1998, foi inaugurado o Centro Integrado de Atendimento ao Adolescente Infrator (CIAAD), extinguindo-se assim o SETREM. Ainda apoiados em Coelho (2006) podemos afirmar que, o Centro Integrado de Atendimento ao Adolescente Infrator (CIAAD) foi projetado para fazer integração operacional dos órgãos do Judiciário, Ministério Público, Defensoria, Segurança Pública, e Assistência Social como determina o artigo 88, V, do ECA. Porém, foram instaladas somente a Delegacia do Adolescente e o Serviço de Atendimento Social (SAS), realizando atendimento de assistência social, serviço psicológico ao adolescente internado provisoriamente.

O relatório de Gestão (PARANÁ, 2007) afirma que a Unidade Social Oficial de Internação de Londrina (USOIL) iniciou suas atividades no dia 01 de julho de 2004. Com a nomeação dos funcionários contratados, (03 administrativos, 03 assistentes sociais, 03 psicólogos, 01 pedagogo, 36 Educadores Sociais e 04 auxiliares de enfermagem) foi promovida, por aproximadamente uma semana, uma capacitação, realizada pelo Instituto de Ação Social do Paraná (IASP). Eram apenas aulas teóricas baseadas na experiência empírica de funcionários que há tempos estavam nessa área de atividade, sendo que a maioria passava uma visão baseada na doutrina da proteção integral. 
A idade média dos servidores contratados estava entre 25 a 35 anos. Poucos atuavam na área anteriormente. Alguns chegaram a se exaurir com aquela capacitação, contudo, para a imensa maioria, que não tinha ideia do que era trabalhar numa unidade de internação de adolescentes autores de infração, e ainda por ser a primeira experiência de capacitação pela qual passavam, não questionavam seu formato/conteúdo. ${ }^{1}$

Foi realizada visita técnica pelos funcionários aprovados em concurso público na recém-construída unidade, em que, após alguns dias, os funcionários tomaram posse dos seus cargos, mas sem receber adolescentes. Nessa época, ninguém tinha ideia do que seria aquilo e como seria a dinâmica. Psicólogos faziam dinâmicas de grupos, outro grupo providenciava um esquema para a rotina e outro grupo liderado por Educadores Sociais que trabalharam no sistema prisional cuidavam de aspectos relacionados à segurança. Enfim, de maneira não integrada, o grupo foi buscando um modelo para se trabalhar na unidade. Em suma, os funcionários foram colocados em atividade sem referências concretas de trabalho e sem nenhum profissional que norteasse as ações, pois o diretor nomeado à época também não possuía experiência na área da socioeducação.

Ainda segundo o relatório de Gestão (PARANÁ, 2007), podemos afirmar que o setor administrativo apresentava muitos problemas. Questões como fornecimento de alimentos e a estrutura necessária para funcionamento, não existiam, o que resume o descaso dos responsáveis com a unidade que surgia, a falta de visão administrativa e política, o desrespeito aos servidores, na época, todos contratados em regime especial temporário.

Com a previsão da chegada dos primeiros adolescentes para agosto de 2004, faltavam ainda os itens mais básicos como roupas, colchões, blusas etc., e apenas com muita pressão por parte dos gestores estaduais da socioeducação, foram chegando alguns itens.

Foi construído um regulamento interno para funcionários e adolescentes, baseado em suposições de como seria a dinâmica na unidade, no entanto, sem a participação de todos envolvidos no processo, o que levou a muitos debates provocados por pontos de vistas divergentes.

\footnotetext{
${ }^{1}$ Um dos autores foi sujeito dessa experiência de formação/capacitação.
} 
Naquele período, a unidade recebeu cerca de 25 adolescentes, e as primeira falhas estruturais começaram a aparecer. Os adolescentes subiam nas paredes dos solários, invadiam outras alas, desafiando os Educadores Sociais. Começaram os xingamentos, e logo vieram as primeiras brigas entre Educadores e adolescentes.

A estrutura arquitetônica era bastante fechada, um contexto com funcionários mal capacitados, despreparados, sem apoio administrativo, com péssima estrutura, sem um especialista na direção e com os adolescentes com alto grau de vulnerabilidade. Ficava claro que a unidade passaria por situações de crise.

Em pouco tempo vieram os conflitos generalizados entre Educadores Sociais e adolescentes. Com a falta de estrutura e despreparo dos funcionários, os adolescentes ficavam muito tempo presos nos alojamentos, gerando mais agressividade. Os atritos se tornaram comuns e foram intensificados pela falta de estrutura pedagógica, de proposta clara do processo socioeducativo e de profissionais com perfil para atuação na área. A unidade chegou a ter 80 adolescentes, ou seja, ter sua capacidade máxima ocupada.

Na época (2004), eram 40 alojamentos com dois lugares cada. Esse padrão ficava comprometido em virtude de alojamentos depredados, sendo assim, às vezes, eram colocados 03 a 04 adolescentes no mesmo alojamento em espaço para no máximo 02. Essa alternativa também era utilizada para aliviar a tensão, porque alguns adolescentes pediam para ficar juntos para alguma atividade lúdica, já que não podiam sair dos alojamentos.

Ameaças eram constantes, tanto entre adolescentes, como entre adolescentes e funcionários, e ainda entre funcionários. Alguns técnicos criticavam muito o processo de trabalho dos educadores, criando desgastes entre os grupos de funcionários. Educadores em constante estado de tensão começaram a ter problemas de saúde, crises de pânico etc. Havia alta rotatividade de pessoal entre os Educadores.

Ainda nesse período, em virtude de situações de crise, foi necessária a intervenção da Tropa de Choque da Policia Militar, em várias oportunidades, em razão de rebeliões: em duas delas com reféns. De todos os lugares dos alojamentos, salas, solários, apareciam grandes e pequenos estoques, ${ }^{2}$ os quais eram retirados, a quilo, a cada revista,

\footnotetext{
${ }^{2}$ Objeto pontiagudo produzido artesanalmente com o objetivo de ser utilizado como arma branca.
} 
cada um maior que o outro. Havia forte pressão da imprensa, assustando ainda mais Educadores Sociais e familiares. Denúncias e ameaças eram frequentes.

Pequenas reformas começaram a ser feitas, contudo, sem melhorar muito a estrutura. A situação melhorava um pouco depois que a Tropa de Choque ia embora. Mediante esse grave quadro, a Unidade, então, sofre intervenção (PARANÁ, 2007).

Uma especialista na área foi convidada para assumir a Direção da Unidade. Isso deu um alívio aos educadores que se encontravam no limite com aquela situação. Mesmo assim, logo no início, uma rebelião tomou grande proporção, principalmente porque a intervenção policial ocorreu tardiamente. Além de vários adolescentes machucados, a Unidade ficou inutilizável. Os adolescentes foram transferidos para a Penitenciaria Estadual de Londrina (PEL) e para o Centro Integrado de Atendimento ao Adolescente Infrator (CIAADI). Os Educadores estavam no limite. Logo foi planejada uma reestruturação total, a Unidade passou por uma reforma grande, eliminando pontos de estoques, isolando as alas, solários, cobrindo e isolando a quadra de esportes (PARANÁ, 2007). Em 2005, a Unidade foi reinaugurada passando a se chamar Centro de Socioeducação - CENSE. ${ }^{3}$

Os Educadores Sociais passaram por três meses de capacitação, abordando temas como pedagogia, psicologia, serviço social, e principalmente segurança preventiva e tática (polícia, defesa pessoal), de forma exaustiva, passaram por mais de 360 horas de curso.

Com a publicação do concurso público para a contratação irrestrita de servidores públicos de carreira, principalmente pelo final do contrato que se aproximava e pela falta de funcionários, o clima começou a ficar tenso novamente. Reclamações sobre desgaste começaram a rondar a unidade, contudo, a situação não se comparava com a do início das atividades em 2004. Boicotes de alguns Educadores começaram a acontecer porque não havia privilégios para o concurso que se aproximava, ao menos era a visão de alguns.

Tal questão se configurou numa falha de planejamento do Estado, que desgastou muito a todos que ali estavam. Mesmo assim houve troca de grande parte de técnicos e funcionários sem maiores transtornos. A área administrativa sofreu com as modificações

\footnotetext{
${ }^{3}$ A inauguração da Unidade dotou o município de Londrina de uma rede completa de serviços para o atendimento destinado às crianças e adolescentes, conforme prevê o Estatuto da Criança e do Adolescente em seu artigo 90, são elas: Orientação e Apoio Sociofamiliar; Apoio Socioeducativo em Meio Aberto; Colocação Familiar; Acolhimento Institucional; Liberdade Assistida, Prestação de Serviços à Comunidade; Semiliberdade e Internação.
} 
instituídas pelo órgão gestor. A saída de parte da alta administração fragilizou novamente o sistema. Isso se refletia na unidade. Havia uma ordem socioeducativa instituída, contudo sem a estrutura técnica competente.

O relatório de Gestão (PARANÁ, 2007) ainda aponta que, apesar de poucos conflitos, havia sempre uma grande ameaça no ar. Os Educadores Sociais instituíram uma nova postura profissional vinculada exclusivamente à segurança, sem, contudo, assimilar a socioeducação como postura, o que o cargo exigia.

Em meados de 2007, houve a maior situação de crise no CENSE Londrina II, quando 02 funcionários foram feitos reféns. Além de 07 adolescentes, os funcionários também foram espancados, sendo necessária a intervenção da Policia Militar, com equipe de negociação e a tropa de Choque para que a ordem fosse restabelecida, o que acabou por ocasionar mudanças significativas na unidade, ou seja, instituiu-se de vez a força de segurança.

Posterior a esse último grande evento, houve uma estabilidade na área da segurança, não havendo eventos que chegassem sequer perto dessa última grande rebelião. Acontecimentos que ocorrem no dia a dia são de ínfima magnitude se comparados às crises anteriores.

\section{A pesquisa}

O presente estudo pretende verificar se existem variações entre a função descrita para o cargo de Educador Social e sua prática. É de suma importância poder sistematizar a compreensão da função de Educador Social prevista nas normativas institucionais, para que assim se possa fazer um estudo comparativo com a sua prática cotidiana, e identificar quais as disparidades entre uma e outra, apontando, assim, caso existam, onde está o agente causador de tal dessemelhança.

Como objetivos específicos, faremos a explanação a respeito da função do Educador Social na busca de um melhor entendimento de sua prática cotidiana. Iremos observar se existem alterações entre o que está descrito para o cargo de Educador Social no Quadro Próprio o Poder Executivo do Estado do Paraná - QPPE/PR. Ainda pretendemos identificar, dentre as competências pessoais descritas para o cargo, se existem aspectos em que haja menor identificação por parte dos Educadores Sociais. 
Vejamos então o que sugere a descrição básica da função e competências pessoais:

Comprometer-se com o processo socioeducativo dos adolescentes em todas as fases, participando da elaboração, execução e avaliação do plano personalizado, com vistas ao desenvolvimento integral, autônomo e responsável. Encaminhar, acompanhar e monitorar os adolescentes nas atividades internas e externas, conforme previstas na agenda sócioeducacional. Planejar e desenvolver em conformidade com a proposta pedagógica da unidade, atividades lúdicas, pedagógicas, sociais, culturais, de rotinas diárias como: alimentação, higiene pessoal e ambiental, junto aos adolescentes, que contribuam para o desenvolvimento de competências para ser e conviver. Realizar efetivamente a segurança preventiva e interventiva junto aos adolescentes, dentro e fora da Unidade, observando os indicadores das situações de crise e seguindo rigorosamente os procedimentos normatizados. Zelar pela segurança do patrimônio, efetuando vistoria sistemática das instalações físicas e de materiais utilizados nas atividades, prevenindo situações de crise. Atuar em equipe cumprindo suas funções e colaborando com os demais, participando da definição de medidas de segurança e das avaliações dos adolescentes, buscando e trocando informações e garantindo o ambiente seguro e educativo da Unidade. Realizar atividades administrativas (PARANÀ, 2005).

$\mathrm{Na}$ verificação breve da descrição, percebe-se que uma vez que se tem o adolescente como protagonista o que (COSTA, 2000, p. 20) o define como o ator principal, ou seja, o agente de uma ação, seja ele um jovem ou um adulto, um ente da sociedade civil ou do Estado, uma pessoa, um grupo, uma instituição ou um movimento social e nessa relação educador/educando, são os dois sujeitos que estão diretamente ligados na busca pelo desenvolvimento pleno do educando e que se indica uma série de características que podem ocasionar uma subjetividade ou mesmo definições variadas como, por exemplo, empatia, assertividade, sensibilidade, desenvolver relacionamentos, resistência à frustração, bom-senso dentre outros.

O documento da descrição do cargo apresenta ainda as competências dos profissionais que devem assumir a função:

São Competências Pessoais: Trabalhar em equipe; Idoneidade; Bom senso; Discrição; Imparcialidade; Autocontrole em situações de risco; Persistência; Resistência à frustração; Respeito às diferenças; Habilidade de administrar conflitos; Princípios e valores morais e éticos; Atitude disciplinadora e de respeito; Equilíbrio emocional e maturidade; Capacidade humana para desenvolver relacionamentos; Sensibilidade; Empatia; Responsabilidade; Prontidão; Habilidade de Comunicação; Assertividade; Bom condicionamento físico; Acuidade visual e auditiva (PARANÁ, 2005). 
São algumas características que têm relação direta com valores que, segundo Gastaldi (apud COSTA, 2000, p. 123), valor é a força capaz de tirar o homem de sua indiferença e provocar nele uma atitude de avaliação porque contribui de alguma forma para sua realização pessoal.

Podemos observar, conforme citado anteriormente, que existe na prática uma linha extremamente tênue no que se refere ao entendimento do vínculo entre educador/educando, possibilitando margens para interpretações dúbias, pois cada educador é um sujeito dotado de crenças e valores, com suas vivências, costumes, enfim, criações distintas, que permitem visões múltiplas de um mesmo fenômeno.

Não nos eximindo deste fato também enquanto socioeducadores, antes mesmo de pesquisadores, devemos atentar-nos para o fato que destaca, segundo Minayo (1994), sobre a ilusão do pesquisador em ver as conclusões, fato que se mostra mais intenso conforme diretamente proporcional à familiaridade com o assunto pesquisado.

Porém, de forma objetiva este estudo pretende entender melhor esta relação de vínculo, para que se possa estabelecer se existe uma dicotomia entre a descrição do cargo e o que ele realmente faz. Uma das questões importantes para o exercício da função do Educador Social também está em saber lidar com esses conflitos, como cita Serrão e Baleeiro, quando nos colocam que:

\footnotetext{
Qualquer que seja a origem deste educador é preciso que ele se distancie, em alguns momentos, para ser espectador da própria prática e assim a percebe com um olhar mais crítico e menos emocional. Em contrapartida, em outros momentos, é necessário inserir-se no meio, fazer parte dele, viver sua realidade, solidarizando-se com ela. E solidarizar-se significa colocar a disposição dos educandos todo saber e bagagem pessoal que possui, buscando em conjunto viabilizar ações, novas experiências, maneiras diferentes de ver, perceber, agir e se relacionar com o mundo (SERRÃO; BALEEIRO, 1999, p. 25).
}

Ainda para exemplificar a questão exposta, podemos nos apoiar na afirmação de Costa (2001, p. 58), que afirma que:

[...] certas concepções de sua função impedem o educador de assumir o papel fundamental que dele se espera na vida do educando: ajudá-lo a encontrar-se a si mesmo e a outro. Qualquer idéia demasiado abstrata e formal de seu papel tende a desmoronar-se diante dos fatos do dia a dia. A prática esta a exigir a todo instante iniciativas enriquecidas e aperfeiçoadas por fatores os mais imprevisíveis. 
Diante disto, optamos por realizar uma pesquisa qualitativa, pois, como sugere Minayo (1994, p. 22), “o conjunto de dados quantitativos e qualitativos não se opõem e ao contrário se complementam com suas realidades interagindo excluindo qualquer dicotomia". Logo, a pesquisa trará consigo dados obtidos a partir de um questionário, o qual foi entregue aos Educadores Sociais do Cense II Londrina.

Considerando que o Cense II Londrina no ano de 2010 possuia 41 Educadores Sociais do sexo masculino, o questionário teve a participação de 14 deste total, o que representa $34,14 \%$, os quais foram escolhidos aleatoriamente. O questionário foi disponibilizado para os educadores, com data de devolução determinada. ${ }^{4}$

Partindo da apresentação da descrição do cargo de Educador Social, conforme o que se encontra no Portal do Servidor, sítio oficial do Governo do estado do Paraná (PARANÁ, 2005), os entrevistados responderam às seguintes questões: 1- Você se identifica com a relação de teoria e prática no que se refere à função que exerce no seu cotidiano? 2- Caso a resposta seja negativa, onde você identifica a diferença entre teoria e prática e por quê?

Receberam o questionário tendo como anexo a descrição de funções do cargo de Educador Social e tiveram um prazo de duas semanas, compreendidas entre 01 de junho a 15 do mesmo mês de 2010 para elaborarem suas respostas e devolvê-las, a fim de que a pesquise pudesse prosseguir.

Partindo deste questionário, identificamos se existe diferença na relação do que estabelece a descrição de função e a prática dos Educadores Sociais do Cense Londrina II.

\section{Entre a socioeducação e a segurança}

Para efeito de apresentação dos dados, os Educadores Sociais serão identificados por números definidos aleatoriamente de 01 a 14, a fim de que se preservem suas identidades.

Do total de 14 (quatorze) respostas dadas à primeira questão (Você se identifica com a relação de teoria e prática no que se refere à função que exerce no seu cotidiano?),

\footnotetext{
${ }^{4}$ Todos aqueles que se dispuseram a responder o questionário assinaram um Termo de Consentimento Livre e Esclarecido.
} 
obtivemos 09 (nove) respostas "NÃO", o que representa 64,3\%, 03 (três) responderam “ÀS VEZES" representando 21,4\% e 02 (duas) respostas "SIM" o que representa 14,3\% do total das respostas.

As explicações dos 09 (nove) entrevistados que responderam "NÃO", sendo direcionados à segunda questão (2- Caso a resposta seja negativa, onde você identifica a diferença entre teoria e prática e por quê?), são apresentadas a seguir.

Um fenômeno a ser considerado é o de que a palavra segurança, embora descrita como um mero complemento na função do Educador Social (que tem como norte formal o processo socioeducativo), aparece em 11 das 14 respostas, representando 78,6\% do total dos que fizeram menção à segurança, como podemos observar nas respostas a seguir: O Educador 4 cita que:

[...] apesar de a função ser de "educar" muitos a confundem com o sistema prisional e deixam transparecer uma ideia vingativa para com o educando, não se importando em desempenhar sua função real.

Fala que traduz o entendimento da função por parte de alguns educadores. Já o Educador 7 comenta sobre uma possível mistura entre socioeducação e segurança, quando cita que:

De forma mais clara o que se torna mais crítico é o meio termo em socioeducação e segurança.

O Educador 9 faz uma comparação com a função do agente penitenciário quando diz que:

Na prática, a função melhor exercida é a de segurança. Na verdade ser educador social é ser como agente penitenciário, só que mais brando.

O comentário remete o socioeducador a uma função diretamente ligada a do agente penitenciário, como se uma tivesse relação direta com a outra. O Educador 10 comenta sobre a falta de credibilidade que vê na função quando, de forma desacreditada, cita que: 
A descrição básica da função do educador é lenda, mas, é pura demagogia. O processo socioeducativo é uma piada, onde não se vê resultados, ou seja, é um puro faz de contas, onde o dinheiro do contribuinte é gasto de forma totalmente ineficaz e sem resultados, pois os valores investidos nesses aprendizes de bandidos, ou bandidos juvenis não têm retorno para a sociedade e muito menos na recuperação dos infratores. Basta ver a porcentagem de reincidência. $\mathrm{Na}$ teoria a função do educador social é fantástica, entretanto o educador existe, na prática, para que os menores infratores fiquem longe do convívio social e assim não continuem a delinquir, mesmo que por um pequeno espaço de tempo.

Esta fala demonstra uma visão que não deveria ser compartilhada por quem tem como função a reinserção de jovens, falta um trabalho específico de conscientização e/ou identificação do trabalho. Já o Educador 12 trás exatamente uma crítica na relação teoria e prática, quando descreve o seguinte:

Na teoria o educador social é responsável por todas as fases do processo socioeducativo, na prática só executa a função de segurança, devido a um processo hierárquico velado entre os setores e o cargo especifico em si, agente de execução, conflitos no modo operacional deste Cense quanto ao pensamento socioeducativo.

Diante destes relatos, percebemos a forte influência que a função de segurança exerce no trabalho cotidiano desses Educadores Sociais, que ao invés de estarem discutindo formas de intervenções pedagógicas, parecem estar alheios a esta questão, não somente por falta de identificação, mas, ao que parece, por falta de um trabalho voltado ao desenvolvimento da função socioeducativa. Os relatos demonstram que não existe qualquer tipo de apoio para que o Educador Social possa exercer o que está descrito no cargo, aparentemente por parte de quem está no comando das diretrizes e deveria priorizar o socioeducador como protagonista da ação socioeducativa, mas o tem como coadjuvante restando-lhes a pecha "de agente penitenciário mais brando".

Aqueles que responderam "NÂO" citaram ainda algumas dificuldades na execução da função, como vemos a seguir na fala do Educador 3:

No cotidiano nos deparamos com situações diferentes das teóricas, na qual não estamos preparados, nem no profissional e nem material e nem no estrutural. Adolescentes com problemas psiquiátricos de difícil diagnósticos, em que o menor não deveria estar internado em unidade socioeducativa, mas sim em clinicas especializadas. Falta de profissionais, falta de capacitação. Há casos em que muitos funcionários são afastados do trabalho por motivo de doenças decorrentes de estresse no trabalho. 
Além da falta de preparo do educador, chama-se a atenção para um problema pontual que é o perfil heterogêneo do adolescente que recebe medida de internação, e, sem dúvida, gera os casos de afastamento por estresse que deveriam ser tratados com maior interesse desde sua prevenção. O Educador 4 comenta que:

\begin{abstract}
As principais diferenças entre a teoria e a prática da função do educador social seriam no que tange às atividades de planejamento em geral, quer do Plano Personalizado de Atendimento, quer na elaboração de atividades lúdicas, pedagógicas, sociais e culturais da unidade. É bem verdade que muitas das vezes esta interação não ocorre por falta de interesse por alguns, mas muitos demonstram grande interesse e potencial para realizá-las, desperdiçando quem sabe uma boa proposta.
\end{abstract}

O Educador comenta sobre uma possível falta de integração do Educador Social nas atividades socioeducativas como se o mesmo estivesse naquele local de trabalho exclusivamente para exercer a função de segurança, pois as decisões não são compartilhadas com eles, de maneira que o potencial humano desses profissionais é desperdiçado no que se refere a ações socioeducativas. 0 Educador 6 aborda a questão da falta de estrutura quando diz que:

Identificar-se significa acreditar na socioeducação sendo executada em condições estruturais e material humano não adequado a sua concretização, não fosse isso[...]

Ele ainda comenta que é possível desenvolver o trabalho, no entanto, o quadro de funcionários defasado e a estrutura precária de trabalho impede que tal trabalho seja desenvolvido. O Educador 9 apresenta os seguintes problemas:

Temos uma relação mais amistosa e em certos momentos conversamos e aconselhamos os internos. Aproveitando-se dessa proximidade, a descrição da função é ampla e não são todos que possuem características iguais para poder cumprir a descrição. Enfim acumulamos basicamente duas funções: $A$ do dialogo e a de conter, limitar, mesmo que para isso seja feito o uso da força.

Este relato deixa muito claro a dicotomia entre socioeducação e segurança, funções distintas, trabalhadas por um mesmo sujeito que sente dificuldade na execução de ambas 
por não se sentir pertencente a nenhuma. 0 educador 11 demonstra estar desmotivado quando comenta que:

Identifico-me apenas com alguns itens na sua integridade (integralidade), porem não há incentivo por parte de quem deveria dar todo suporte necessário para que eu possa os executar.

Este ainda explicita a falta de incentivo para o desenvolvimento da função de socioeducador, motivo talvez que leve a se refugiar nas ações voltadas para a segurança. Por fim, o Educador 13 comenta que:

Não tem espaço para aperfeiçoar a comunicação com os educandos.

Ele justifica sua resposta de não desenvolver um trabalho socioeducativo como a função descrita com uma crítica à metodologia de trabalho, percebe que existe uma empatia e uma predisposição para estabelecer tal comunicação, mas não existe aproveitamento dessas disposições, ficando os educadores alheios a qualquer tipo de intervenção no âmbito educacional.

Existe um entendimento geral nas falas dos Educadores Sociais que demonstra um descontentamento na execução da função, com explanações que atestam que a descrição proposta para a função de Educador Social é diferente da prática, os relatos apontam para uma percepção de que há disponibilidade para tal, porém eles não identificam condições de trabalho para se desenvolver a função.

Os Educadores 1, 2 e 8 responderam que somente "ÀS VEZES" desenvolvem a função conforme a descrição e justificam. O Educador 1 comenta:

[...] mesmo sabendo das limitações que encontramos no dia a dia, já que muitas vezes somos impedidos de colocar em prática aquilo que planejamos devido à falta de autonomia. A dificuldade de participar do planejamento, da elaboração dos programas socioeducativos, acaba desmotivando o educador de lutar por um maior envolvimento e comprometimento com seu trabalho. Com isso, fica muitas vezes predominando as medidas de segurança de forma a mudar o foco principal que é a ressocialização do menor infrator.

Percebemos, nesta fala, que o sujeito tem total clareza de como deveria ser a função propriamente dita, mas não encontra condições para que se possa desenvolvê-la, 
o que resulta em desmotivação. Esse registro demonstra a falta de motivação causada por falta de medidas que envolvam o educador na ação socioeducativa propriamente dita, restando-Ihe apenas a função de segurança.

$\mathrm{O}$ relato que segue, do Educador 2, tem uma proximidade com o anterior, como podemos notar a seguir:

[...] não existe a participação efetiva do educador na elaboração, execução $e$ avaliação do Plano Personalizado de Atendimento; Qual a proposta pedagógica da unidade? Então como podemos planejar e desenvolver atividades corretas; Portanto, o que nos resta, efetivamente, é participar realizando atividades relacionadas à segurança da unidade como um todo.

Como se pode notar, o relato deste Educador traduz de forma clara a falta de opção no desenvolvimento da função socioeducativa, excluído daquilo que está descrito para ser sua função, como se ele não fosse importante nesse processo. 0 Educador 08 finaliza o raciocínio dos três entrevistados que responderam desenvolver a função de Educador Social, "ÀS VEZES", com o seguinte relato:

Em parte, no papel tudo é bonito. Não aparecem as dificuldades, falta de recurso, falta de capacitação e treinamento adequado, lotação nas unidades, também não aparece a individualidade do educador que interfere na teoria.

O relato deste sujeito demonstra que entre o que está descrito e a prática cotidiana existem diferenças, e mais que isso, para ele não existe um trabalho voltado a melhorar o desempenho dos que realizam a atividade, seja com treinamento/capacitação ou com recursos e trabalhos específicos de motivação.

Os Educadores Sociais que responderam "SIM" foram 2, e mesmo não sendo dirigidos pelo questionário comentaram a resposta de maneiras distintas. O primeiro, Educador 5, admite que, apesar de se identificar com o que está descrito como função do Educador Social, não vê isso ser realizado de forma integral:

[...] apesar de acreditar que o rol de descrições e competências pessoais não são realizadas em sua totalidade por causa da individualidade de cada um, porque sempre tendemos para o lado em que temos mais predisposição ou facilidade para a execução. 
Este relato chama a atenção, pois vale informar que, na realização do concurso para a função propriamente dita, deu-se grande importância à questão do condicionamento físico, ao invés de se priorizar pessoas com perfil para o trabalho socioeducativo, trazendo um reflexo direto e presente no relato deste Educador.

Para concluir, temos o Educador 12 que se deteve ao solicitado e se limitou a uma resposta direta, sem comentários: Sim.

Apenas e tão somente sim. É uma pena que sobre função tão complexa e que lida com um público ainda mais complexo, que são os adolescentes, alguém se atenha a uma resposta tão breve, mas em compensação com tamanha significância, quando se busca entender de o porquê de tamanha brevidade.

\section{Considerações finais}

Como podemos perceber, há um descompasso, observado pelos Educadores Sociais, na relação entre a descrição de suas funções se comparada ao que realizam no cotidiano da prática profissional. Verificamos que estes fazem críticas sobre a forma como são posicionados institucionalmente. Tais profissionais creditam tal descontentamento ao fato de a instituição, na prática, esperar mais dos aspectos relacionados à segurança do que à socioeducação. Apontam, ainda, que se sentem apartados das decisões sobre a forma de trabalho, o que proporciona um cenário de tensões na relação com toda a equipe da unidade.

A falta de autonomia e propostas de trabalho transforma os Educadores Sociais em executores de uma proposta com ampla resistência para sua execução, ficando uma latente sensação de que não existe participação efetiva para as decisões de equipe. $\mathrm{A}$ participação do Educador Social na equipe de referência do adolescente, que viabiliza o atendimento personalizado, é reduzida, muitas vezes, ao representar a segurança, trabalhando com uma estrutura física, material e humana aquém do adequado.

Sem dúvida, esse conjunto de dificuldades contribui para que, a cada dia, se desconstrua elementos da socioeducação no imaginário dos Educadores Sociais, fortalecendo cada vez mais um estereótipo daquele que atua focado na segurança e disciplina, sem atuar com intervenções educativas, o que seria o desejado. 
Os episódios citados, nos quais houve inúmeras crises, motins e rebeliões, contribuíram para que haja um distanciamento entre o Educador Social e os educandos, pois esta é uma questão que não foi trabalhada para que houvesse uma alteração no sentimento inicial de raiva, sendo assim esse sentimento ainda hoje permeia muitos dos que vivenciaram esta fase, interferindo negativamente na socioeducação.

Percebemos, ainda, uma falta de trabalho em equipe, em que setores atuam de forma isolada, não havendo uma real interdisciplinaridade, o que minimiza as qualidades de todos os setores. Tal fato também contribui para que o Educador Social priorize ações da segurança, o que, sem dúvida, reduz a possibilidade da realização da socioeducação em todos os seus aspectos.

A atuação focada na segurança traz a tendência de um conflito entre Educadores Sociais e educandos, no qual ambos acabam se vendo em posições antagônicas, ao invés de construir, de forma conjunta, perspectivas para o adolescente, trabalhando com encaminhamentos diversos e cumprindo a sua primordial função de garantia dos direitos dos adolescentes que cumprem medida socioeducativa de internação.

\section{Referências}

BRASIL. Lei n. 8.069 de 13 de julho de 1990. Dispõe sobre o Estatuto da Criança e do Adolescente e dá outras providências. Disponível em:

<http://www.planalto.gov.br/ccivil_03/Leis/L8069.htm>. Acesso em: 18 mar. 2010.

. Secretaria Especial dos Direitos Humanos. Sistema Nacional de Atendimento Socioeducativo - SINASE. Brasília: CONANDA, 2006.

COELHO, C. S. S. Vivenciando medidas socioeducativas em Londrina: um olhar a partir de Jovens Presos. 2006. Monografia (Pós-Graduação em Serviço Social e Políticas Sociais) Universidade Estadual de Londrina, Londrina.

COSTA, A. C. G. Pedagogia da presença: da solidão ao encontro. 2. ed. Belo Horizonte: MODUS Faciendi, 2001.

Protagonismo juvenil: adolescência, educação e participação democratica.

Salvador: Fundação Odebrecht, 2000.

FREIRE, P. Pedagogia da autonomia: saberes necessários a prática educativa. 25. ed. São

Paulo: Paz e Terra, 2002.

INSTITUTO DE AÇÃO SOCIAL DO PARANÁ - IASP. Compreendendo o adolescente. Curitiba, 
2006. (Cadernos do IASP).

MINAYO, M. C. S. et al. (Org.). Pesquisa social: teoria, método e criatividade. Petrópolis: Vozes, 1994.

PARANÁ. Cargo: agente de execução AE. 2005. Disponível em:

<http://www.portaldoservidor.pr.gov.br/arquivos/File/antigos/54/perfil_profis_funcao_a g_exec_res_7193_2005.pdf>. Acesso em: 18 mar. 2010.

Secretaria de Estado da Criança e da Juventude. Centro de Socioeducação de Londrina II. Relatório de gestão. 2007. Disponível em:

<http://www.secj.pr.gov.br/modules/conteudo/conteudo.php?conteudo=28>. Acesso em: 20 maio 2010.

SERRÃO, M.; BALEEIRO, M. C. Aprendendo a ser e a conviver. São Paulo: FTD, 1999.

Recebido em: 01/10/2011

Aprovado em: 18/12/2011 